\title{
Age and Injury Patterns of Female Survivors of Different Alleged Sexual Assaults Examined in the Teaching Hospital Anuradhapura, Sri Lanka
}

\author{
Senanayake S.M.H.M.K. \& Karunathilaka H.A.
}

Teaching Hospital, Anuradhapura, Sri Lanka

\begin{abstract}
During the year 2014, two hundred and seventy (270) victims of sexual assaults had been medico-legally examined in the Teaching Hospital Anuradhapura. Twenty seven (27) were males and two hundred forty three (243) were females. Retrospective study was done by collecting data from medico-legal reports of all alleged sexually assaulted female survivors. Eleven different categories were identified among alleged sexual assault cases according to the main complaint of the victims. They are:-(1) Eloped with boyfriend before the age of 16 years (age for consenting sex)- 108, (2) Consenting sexual intercourse - 41, (3) Fondling/ Touching- 31, (4) Alleged rape and attempted rape (non-consensual sexual intercourse)- 30, (5) Intercrural intercourse (thigh intercourse)- 18, (6) Anal intercourse5, (7) Verbal abuse- 5, (8) Abduction(parents suspected sexual assault)- 3, (9) Fingering-1, (10) Exhibition of genitalia- 1, (11) Naked photographs taken after intercrural intercourse-1.
\end{abstract}

During the year 2014, females between the age of 4 and 78 were sexually assaulted in Anuradhapura district. The age range varies with different sexual assaults. The participation in eloping is seen among females between the ages of 12 and 17 years with the maximum number at 15 . Consenting sexual intercourse is seen between 12 and 32 years with the maximum number at 15 . Fondling and touching were reported between 5 and 42 years with maximum cases at 14. Alleged rape and attempted rape cases are reported between 11 and 78 years with maximum numbers at 13 and 14 years.
Intercrural intercourse cases are reported between 4 and 19 years with maximum number at 14 years. Anal intercourse is reported between 5 and 29 years. Sexual verbal abuse is seen at the age of 16 and 18 years. Only case of fingering reported was of a 9 year old, the exhibition case was of 12 year old and the naked photographs taken was of 11 year old.

When examining the victims of sexual assaults of fondling / touch, intercrural intercourse, verbal abuse, abduction and exhibition, physical injuries were not expected and none was found. With regards to victims of elope and consensual sexual intercourse, hymeneal tears were the only findings, except in one case which showed a vulval contusion at 6 o'clock position without hymeneal tear. Single hymeneal tear is the commonest type of genital finding and it is commonly situated at 6 o'clock position. Where there were two hymeneal tears, they were not symmetrically distributed around 6 o'clock position. Bodily injuries were seen only in 5 cases of alleged attempted rape category out of two hundred and 270 alleged sex assaults. Absence of bodily injuries cannot be used to suggest consent or to exclude the victims clinical history in relation to sex assaults during court trials.

Awareness programs to encourage victims to report to police soon after sexual assaults, clinical forensic medicine specialists for major medico-legal units, colposcopic examination of vagina and devices to detect deep skin contusions are the improvements needed. 
Key words: Sexual assaults, intercrual intercourse, elope, rape, hymeneal tears

Corresponding author:

dilruksena62@yahoo.co.uk

\section{INTRODUCTION}

All suspected sexual assault cases of the Anuradhapura district are referred to the Teaching Hospital Anuradhapura (THA) because medico-legal examination of the sexual assault survivor is very important in court trials to prove the type of sexual assault, physical evidence of the assault and to trace evidence to link the perpetrator. Medico-legal examination is usually performed by a forensic medicine specialist or an experienced medico-legal practitioner. During the year 2014,two hundred and seventy (270) victims of sexual assaults had been medico-legally examined in the Teaching Hospital Anuradhapura. Twenty seven (27) were males and two hundred fourty three (243) were females. All had been sexually assaulted by males. This study shows the general picture of the sexual assaults in the Anuradhapura district during the year 2014. The aim of the study is to find the different ages of female victims of different sexual assaults and the injury pattern at the time of medico-legal examination.

\section{MATERIALS AND METHOD}

Retrospective study was done by collecting data from medico-legal reports of all alleged sexually assaulted female survivors examined in the medico legal unit of the Teaching Hospital Anuradhapura. Age of the victim and information regarding the injuries were collected from hundred and fifty three (153) medico legal examination forms examined by a consultant judicial medical officer and hundred and seventeen (117) medico-legal examination forms examined by a senior medico legal officer. They were analyzed according to the main complaint of the victim, age of the victim and injury pattern.

\section{RESULTS}

Eleven different categories were identified among alleged sexual assault cases according to the main complaint of the victims. They are: (1) Eloped with boyfriend before the age of 16 years (age for consenting sex)- 108, (2) Consenting sexual intercourse - 41, (3) Fondling/ Touching - 31, (4) Alleged rape and attempted rape (non-consensual sexual intercourse)- 30, (5) Intercrural intercourse (thigh intercourse)- 18, (6) Anal intercourse5, (7) Verbal abuse- 5, (8) Abduction(parents suspected sexual assault)- 3, (9) Fingering-1, (10) Exhibition of genitalia- 1, (11) Naked photographs were taken after intercrural intercourse-1. 
Different ages of victims of elope and consensual sexual intercourse groups

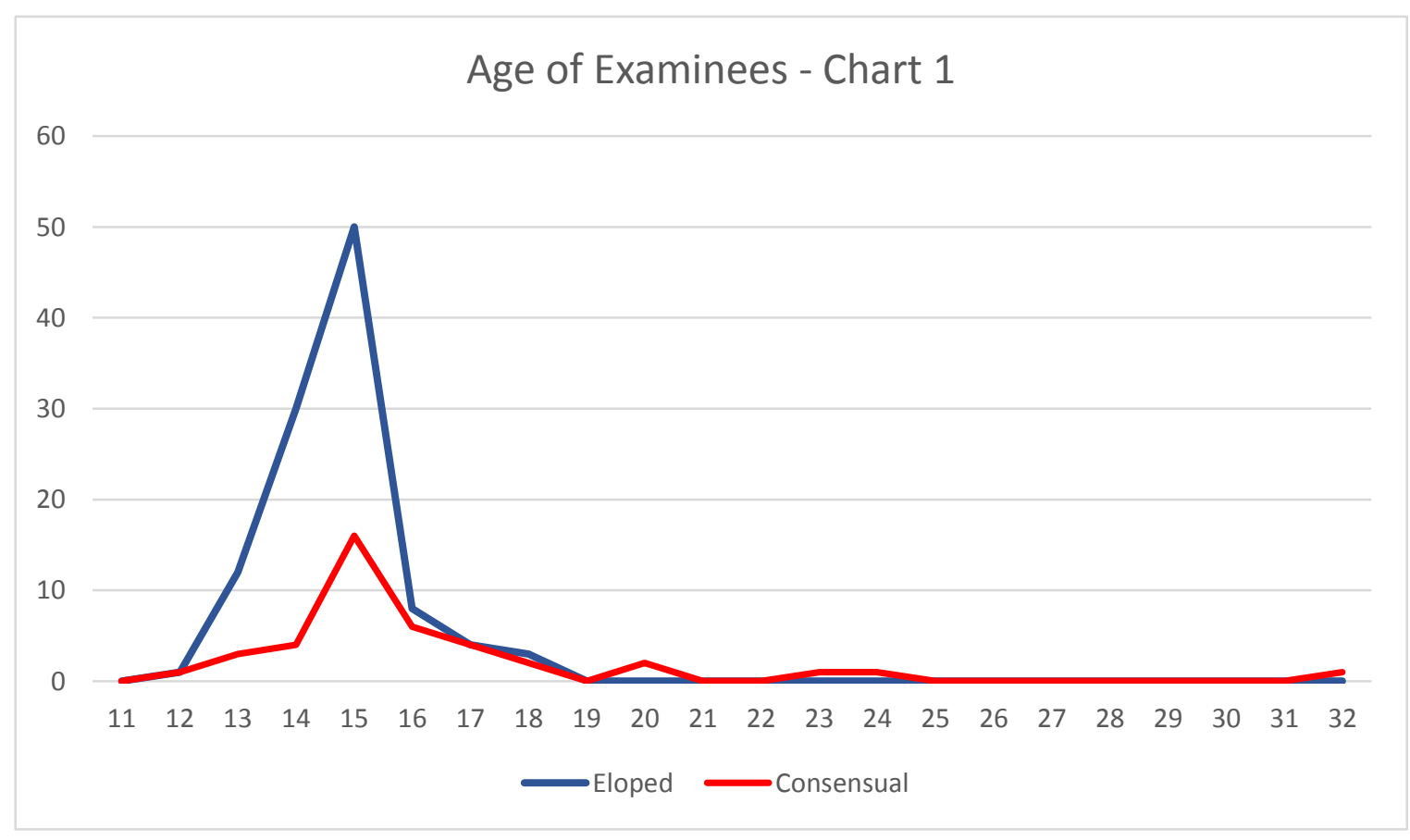

Different ages of victims of touch, rape and intercrural intercourse groups

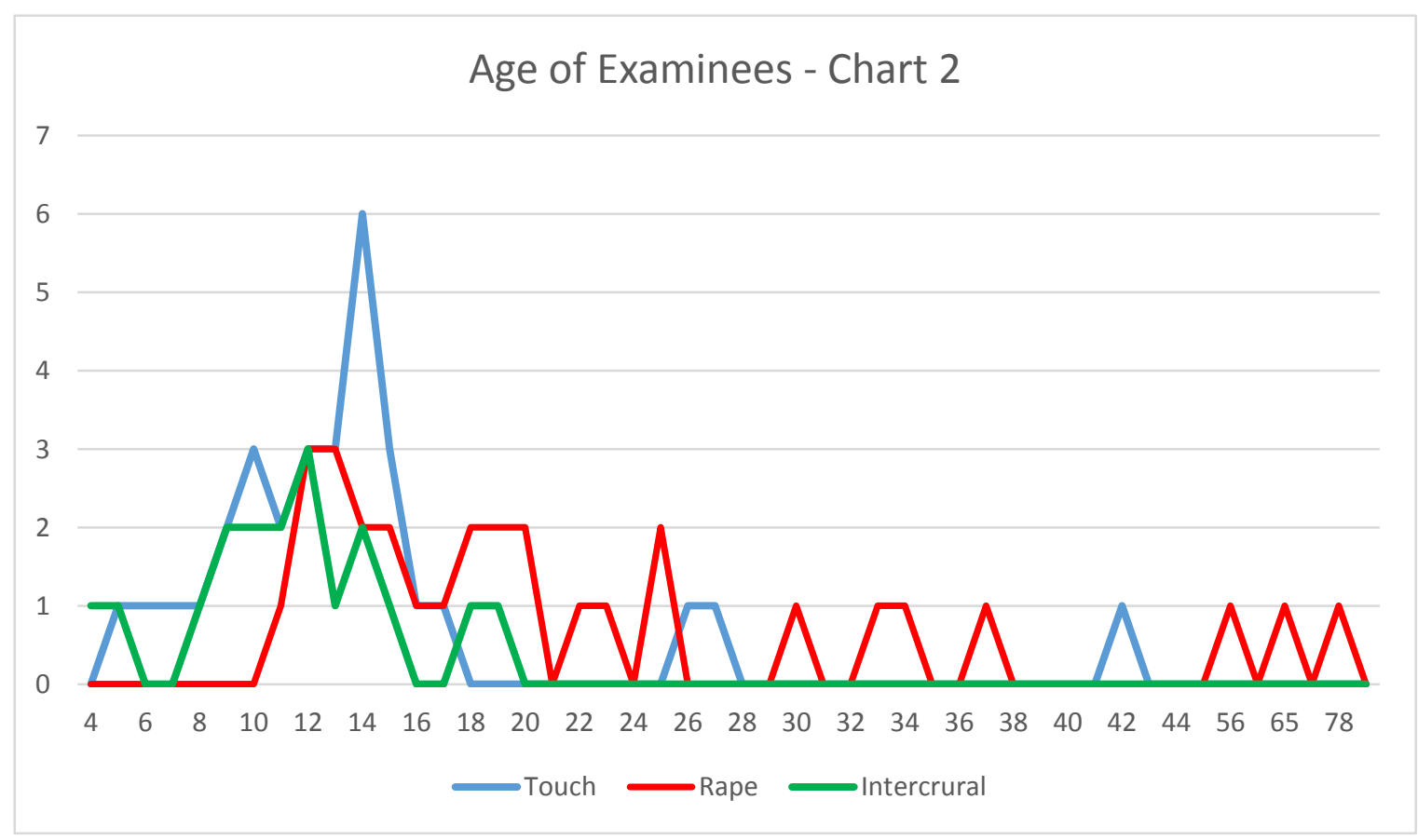


Different ages of victims of anal abuse, verbal abuse, abduction, fingering and exhibition groups

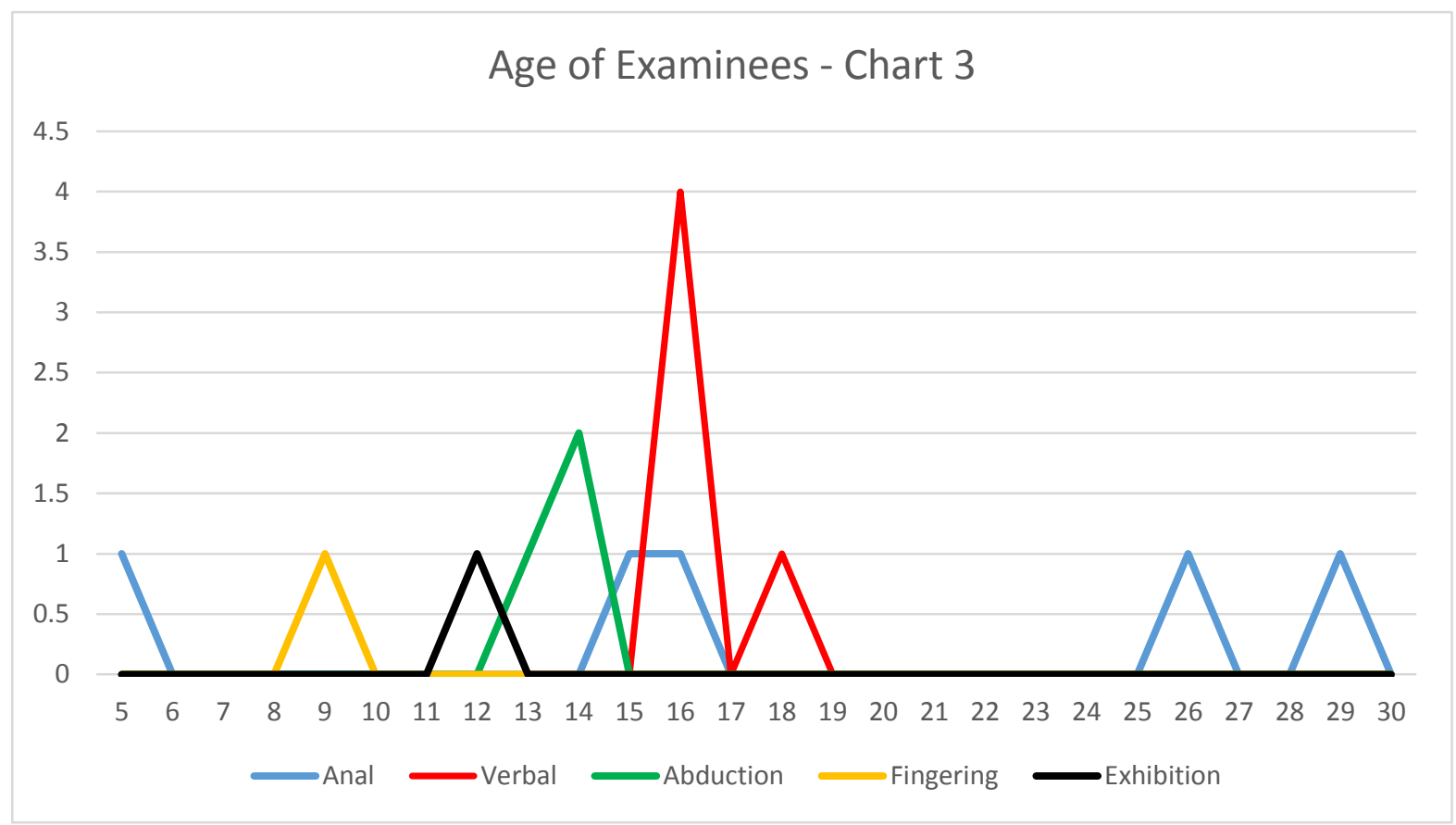

\section{Injury pattern at the time of examination}

(1) Eloped with boyfriend before the age of 16 years.

No bodily injuries were found in any case.

Findings of Genital Examination with the number of cases

\begin{tabular}{|l|l|}
\hline Type of Findings & No. of cases \\
\hline No history of sexual intercourse and no genital injuries & 12 \\
\hline History of sexual intercourse present but no genital injuries & 16 \\
\hline Attenuation of hymen & 11 \\
\hline Large hymeneal orifice ( two adult finger size) & 11 \\
\hline Fimbriated hymen & 12 \\
\hline Contusion at 6 o'clock position of vulva & 01 \\
\hline Hymeneal gap between 5 and 7 o'clock position of hymen & 02 \\
\hline Partial hymeneal tears at 3 and 6 o'clock positions & 01 \\
\hline Complete hymeneal tears & 52 \\
\hline
\end{tabular}


Sites of 52 complete hymeneal tears with number of cases

\begin{tabular}{|l|l|l|}
\hline No. Hymeneal Tears & Site of tears & No. of cases \\
\hline \multirow{4}{*}{ Single Hymeneal Tear } & 6 o'clock position & 28 \\
\cline { 2 - 3 } & 7 o'clock position & 05 \\
\cline { 2 - 3 } & 5 o'clock position & 03 \\
\cline { 2 - 3 } & 3 o'clock position & 01 \\
\hline \multirow{5}{*}{ Two Hymeneal Tears } & 4 and 7 o'clock positions & 03 \\
\cline { 2 - 3 } & 5 and 7 o'clock positions & 03 \\
\cline { 2 - 3 } & 6 and 7 o'clock positions & 02 \\
\cline { 2 - 3 } & 5 and67 o'clock positions & 01 \\
\cline { 2 - 3 } & 3 and 6 o'clock positions & 01 \\
\cline { 2 - 3 } & 4 and 6 o'clock positions & 01 \\
\cline { 2 - 3 } & 6 and 8 o'clock positions & 01 \\
\cline { 2 - 3 } & 4 and 8 o'clock positions & 01 \\
\cline { 2 - 3 } & 5 and 8 o'clock positions & 01 \\
\hline Four Hymeneal Tears & $3,6,7$ and 9 o'clock positions & 01 \\
\hline
\end{tabular}

(2) Consensual sexual Intercourse

Consensual sexual intercourse was the complaint of 41 victims. Thirty four (34) were below 16 years and were produced under the law of statutory rape. Two of them were pregnant. Out of 7 adult females, 5 filed complaints at the police station because of the refusal of marriage by boyfriends after engaging in consensual sexual intercourse and two of them were referred by clinicians following ingestion of poisons due to refusal of marriage.

Bodily injuries were not seen in this group.

\section{Findings of Genital Examination with the number of cases}

\begin{tabular}{|l|l|}
\hline Injury Pattern & No. of cases \\
\hline Complete hymeneal tears & 28 \\
\hline Large hymeneal orifice more than 2 adult fingers & 04 \\
\hline No hymeneal tears with hymeneal orifice one adult finger size & 03 \\
\hline Attenuated hymen & 05 \\
\hline Contusion of 6 o'clock position of vulva without hymeneal tears & 01 \\
\hline
\end{tabular}

Site of hymeneal tears with number of cases

\begin{tabular}{|l|l|l|}
\hline No. of hymeneal tears & Site of tear & No. of cases \\
\hline \multirow{5}{*}{ Single hymeneal tears } & 6 o'clock position & 23 \\
\cline { 2 - 3 } & 3 o'clock position & 01 \\
\cline { 2 - 3 } & 7 o'clock position & 01 \\
\cline { 2 - 3 } & 8 o'clock position & 01 \\
\hline Two hymeneal tears & 4 and 6 o'clock positions & 01 \\
\hline Four hymeneal tears & $3,6,7$ and 8 o'clock positions & 01 \\
\hline
\end{tabular}


(3) Fondling and Touch - No injuries were found

(4) Rape and attempted rape

\begin{tabular}{|c|c|c|}
\hline \multicolumn{2}{|l|}{ Genital Findings } & No. of cases \\
\hline \multicolumn{2}{|l|}{ No genital injuries } & 08 \\
\hline \multicolumn{2}{|l|}{ Attenuated hymen } & 05 \\
\hline \multicolumn{2}{|l|}{ Large hymeneal orifice } & 01 \\
\hline \multicolumn{2}{|c|}{$\begin{array}{l}\text { Healed hymeneal tear at } 6 \text { o'clock position and contusion at } 3 \text { o'clock } \\
\text { position }\end{array}$} & 01 \\
\hline \multicolumn{2}{|c|}{ victim has married after the incident } & 01 \\
\hline \multicolumn{2}{|c|}{$\begin{array}{l}\text { history of childbirth after incident and hymeneal gap between 3-9 o'clock } \\
\text { positions }\end{array}$} & 01 \\
\hline \multirow{4}{*}{$\begin{array}{l}\text { Single Hymeneal } \\
\text { Tear }\end{array}$} & 6 o'clock position & 01 \\
\hline & 7 o'clock position & 02 \\
\hline & 3 o'clock position & 01 \\
\hline & 5 o'clock position & 01 \\
\hline Two hymeneal tears & 5 and 7 o'clock positions & 01 \\
\hline
\end{tabular}

Bodily injuries were seen in 5 cases of alleged attempted rape. They were married women.

\section{Site of bodily injuries with the number of cases}

\begin{tabular}{|l|l|}
\hline Sites of bodily injures & No. of cases \\
\hline $\begin{array}{l}\text { Contusion on right forearm, abrasion on right side of neck and on left } \\
\text { forearm. }\end{array}$ & 01 \\
\hline $\begin{array}{l}\text { Contusion on right side of head, abrasions on left side of chest, back, right } \\
\text { thigh, right lower leg, left ankle }\end{array}$ & 01 \\
\hline $\begin{array}{l}\text { Two finger nail abrasions on left side of neck, bite mark on right breast, } \\
\text { abrasion on right shoulder, 5 finger nail abrasions on right upper arm, } \\
\text { abrasion on back of right elbow, on left upper arm, on back of right hand, } \\
\text { on right thigh, on right knee, on left lower leg and contusion on right side of } \\
\text { head }\end{array}$ & 01 \\
\hline Two contusions of neck & 01 \\
\hline $\begin{array}{l}\text { Contusion on left side of chin, two abrasions on neck and an abrasion on } \\
\text { lower leg. }\end{array}$ & 01 \\
\hline
\end{tabular}

(5) Intercrural intercourse (thigh intercourse)- No injuries found

(6) Anal intercourse- no bodily injuries were found. Some cases showed anal tears.

\section{Different findings of the anus with number of cases}

\begin{tabular}{|l|l|l|}
\hline \multicolumn{2}{|l|}{ Injury Pattern } & No. of cases \\
\hline No injuries & 02 \\
\hline \multirow{3}{*}{ Anal tears } & Single tear at 6 o'clock position & 01 \\
\cline { 2 - 3 } & Single tear at 12 o'clock position & 01 \\
\cline { 2 - 3 } & Three tears at 12,2 and 6 o'clock positions & 01 \\
\hline
\end{tabular}


(7) Verbal abuse- No physical injuries expected and none found.

(8) Abduction- Even though parents suspected sexual assaults, boyfriends had abducted girls there was no history of sex. No injuries were found on the body or genitalia.

(9) Fingering-Complete hymeneal tear at 12 o'clock position

(10) Exhibition of genitalia- no injuries expected and no injuries found

\section{DISCUSSION}

Anuradhapura district is considered as a district common for sexual assaults ${ }^{1}$. Sexual assault is any involuntary sexual act in which a person is coerced or physically forced to engage against their will, or any nonconsensual sexual touching of a person. Sexual assault is a form of sexual violence, and it includes penetration (such as forced vaginal, anal or oral penetration or drug facilitated sexual assault), groping, forced kissing, child sexual abuse, incest, torture of the person in a sexual manner and sexual harassments (verbal or physical conduct of a sexual nature that affects an individual's work or school performance).

But in this article, cases are discussed according to the main complaint of the victim in medico-legal viewpoint. According to the complaints of the victims, eleven different categories were found among alleged sexual assault cases of females- (1) Eloped with boyfriend before the age of 16 years-/age for consenting sex- $45 \%$, (2) Consenting vaginal intercourse with underage girls and subsequently refusal of marriage-18\%, (3) Fondling/ Touching - 13\% (4) Alleged rape and attempted rape- $13 \%$ (5) Intercrural intercourse ( thigh intercourse)-.4\%, (6) Anal intercourse-2\%, (7) Sexual verbal abuse- $2 \%$, (8) Abduction- $1.5 \%$, (9) Fingering-0.5\%, (10) Exhibition of genitalia- $0.5 \%$, (11) Naked photographs were taken after intercrural intercourse- $0.5 \%$.

In many jurisdictions, the term 'sexual penetration' is being used instead of 'sexual intercourse'. Sexual penetration includes sexual intercourse, anal intercourse, cunnilingus, fellatio or any other intrusions involving any part of a human body or of any object into the genital or anal opening of a person's body ${ }^{2}$. But in this study, sexual intercourse, anal intercourse, oral intercourse and fingering are separately discussed because in Sri Lanka the term "sexual penetration" is not in use. Sexual intercourse (vaginal intercourse) without valid consent is punished under law of rape and all other penetrations are punished under "grave sexual abuse". Twenty percent $(20 \%)$ of cases consist of non penetrative sexual activities like intercrural intercourse, fondling, exhibition of genitalia and verbal abuse.

Even though cases were categorized in to 11 groups according to the main complaints, they belong to different legal and psychosocial groups. Cases of intimate partner violence are presented as refusal of marriage after consensual sexual intercourse and anal intercourse. Child sexual abuse ${ }^{3}$ cases were presented under all complaints and became the majority $91.7 \%$ (223 cases). Sexual assault in workplace is another emerging problem in the world ${ }^{4}$, and one case is found in this study.

Sexual harassment is another interesting topic under discussion in developed countries. Sexual harassment is intimidation, bullying or coercion of a sexual nature, or the unwelcome or inappropriate promise of rewards in exchange for sexual favors. Verbal Sexual harassment was found in the study.

\section{Age of the victims}

During the year 2014, females between the ages of 4 years and 78 years were sexually assaulted in Anuradapura district. The age range varies with different sexual assaults. Participation in eloping is seen in females between the ages of 12 and 17 years with the maximum number at 15 . Consenting sexual intercourse is seen between 12 and 32 years 
with the maximum number at 15 . Females under 16 years were produced for medicolegal examination because engaging in sexual activity is a statutory crime due to absence of legally valid consent. Females above 16 were reported because their boyfriends refused to marry them. Two girls were reported by clinicians because they ingested poison to commit suicide. Fondling and touching were reported between 5 and 42 years with maximum cases at 14. Alleged rape and attempted rape cases are reported between 11 and 78 years with maximum numbers at 13 and 14 years. Intercrural intercourse cases are reported between 4 and 19 years with maximum number at 14 years. Anal intercourse is reported between 5 and 29 years. Sexual verbal abuse is seen at the ages of 16 years and 18 years, maximum being at the age of 16 years. Abduction is not a sexual assault but victims were produced for medico-legal examination to eliminate suspicion of any sexual assault because parents were suspicious of vaginal intercourse. Victims were 13 and 14 years old with the maximum number at 14 . Only case of fingering reported was of a 9 year old, the exhibition case was of a 12 year old and the naked photographs taken was of a 11 year old.

Elderly sexual assault is considered as victimization of persons over the age of 60 ;Most of whom suffer from decreased functionality, frailty, and weakness and therefore are reliant on caretakers. Only a small percentage of elderly victims report it to the police. Physical signs that an elder is being sexually assaulted include increased vaginal tearing, bleeding, bruising, infection, pelvic injury, soft tissue or bone injury. In this study, out of 30 alleged rape/

attempted rape victims two were elderly women $(6.6 \%)$.

Teenage elope and consensual sexual intercourse is very common in Anuradapura district and it leads to pregnancy, criminal abortions and suicides 5 . This study shows hundred and forty two $(142,52.5 \%)$ of such cases during the year with two attempted suicides. Since $43 \%$ of all cases had been medico-legally examined by a senior medico legal officer, it is rational to strengthen clinical forensic medicine subspecialty in Sri Lanka and appoint such specialists to stations where more clinical cases are medico-legally managed.

\section{Injury patterns of different complains}

In the examinees for Fondling / touching, intercrural intercourse, verbal abuse, abduction and exhibition, no physical injuries were expected and none were found. But theoretically, redness of the skin is a possibility. Medico-legal examination soon after assault and devices to detect deep skin contusions are the improvements needed to develop medical evidence. Intercrual intercourse ${ }^{6}$ is discussed in medical literature mainly in relation to small children. Four percent $(4 \%)$ of cases of intercrual intercourse in this study group, mainly in post puberty girls in Sri Lanka, may be due to the cultural reasons such as respect for the virginity.

In elope and consensual sexual intercourse groups, hymeneal tears were the only findings except in one case which showed a vulval contusion at 6 o'clock position without hymeneal tear. Single hymeneal tear is the commonest type of genital finding and it is commonly situated at 6 o'clock position. When there are two hymeneal tears they were not symmetrically distributed around 6 o'clock position as 5 and 7 or 4 and 8 , instead they were found at 4 and 7, 6 and 7, 5 and 7, 3 and 6,8 and 5 o'clock positions. In the elope group, there are cases where history of sexual intercourse is available but hymeneal tears were absent. This situation is possible due to two reasons;-Either the victim had recognized non penetrative intercrual intercourse as sexual intercourse or false history was produced to get the parental permission for marriage.

Attenuated hymen is an important finding indicating repeated vaginal penetration ${ }^{7}$. Large hymeneal orifice (two adult fingers size) without hymeneal tears is a practical challenge for the forensic medicine 
practitioner to express an opinion about vaginal penetration. In high court trials, lawyers expect to differentiate congenitally large hymeneal orifice and large hymeneal orifice due to previous sexual intercourse. Therefore, "large hymeneal orifice" needs further research to identify causes.

Injury pattern at the time of examination depends on the time duration between sexual assault and medical examination, force applied, resistance of the victim and local condition of the vagina ${ }^{8}$. Commonest finding is the complete hymeneal tear. Partial hymeneal tear was found only in one case indicating it as an uncommon finding in sex assaults. Minor vaginal tears are expected in recent vaginal intercourse;- Hence, Sri Lankan forensic medicine practitioners need to start finding minor tears of vagina with the help of colposcopy ${ }^{9}$. As the result of continuous training programs, police officers promptly produce sex assault victims to the forensic medicine practitioners. On the other hand, victims present themselves to the police after a considerable delay. Therefore, public awareness programs can improve the situation.

In the victims of rape and attempted rape, commonest genital finding was the healed hymeneal tears due to previous consensual sexual intercourse. Even though lawyers and general public expect to find bodily injuries in rape and attempted rape victims, injuries were found only in $16.6 \%$ (5 adult victims out of 30) cases. Absence of injuries could be due to surrender with fear, injury disappearance with time or false complaints. During the history taking from

the victims, more attention is required to find the reasons for not sustaining injuries. Absence of injuries should not be used to suggest consent for sex or to exclude the history of the victim in court trails. None of the children had bodily injuries. It confirms that sexual child abuse is not associated with physical child abuse.

Three victims of anal intercourse $(60 \%)$ had anal tears. During history taking, it is important to obtain details about penetration of penis through anus. Moving the penis between buttocks from behind is also identified as anal intercourse by teenagers. The fingering case showed a hymeneal tear at 12 o'clock position. It was not in accordance with the common expectation of hymeneal tear around 3 or 9 o'clock position with foreign body penetration such as a finger.

\section{CONCLUSION}

Females between the ages of 4 years and 78 years had been subjected to sexual assaults in Anuradhapura district during the year 2014 . Eloping with the boyfriend was the commonest presentation (40\%). Statutory rape identified in the study as elope and consensual sexual intercourse before the age of 16 years $(52.5 \%)$, was the major criminal offence among alleged sexual assaults in Anuradhapura district.

Females between the ages of 11 years and 78 years were subjected to alleged rape or attempted rape with the maximum cases at the age of 13 and 14 years. Bodily injuries were seen only in 5 cases of alleged attempted rape category out of two hundred and seventy (270) alleged sex assaults. Absence of injuries cannot be used to suggest consent for sex or to exclude the history of the victim in court trails.

Awareness programs to encourage victims to report to police soon after sexual assault, clinical forensic medicine specialists for major medico-legal units and devices to detect deep skin contusions are the improvements needed.

\section{REFERENCES}

1. Colombage SM, Dasanayake PB, Waidyarathna DL. A study on child abuse in Anuradapura, Colombo South and Rathnapura. 2005: $1^{\text {st }}$ ed. Atlas Hall Ltd; Colombo.pp-5,6

2. Nadesan K. Rape: an Asian perspective. Journal of Clinical Forensic Medicine. June 2001; 8(2), 93-98

3. Anthony P, Judith A. A clinical-demographic study of sexually abused children. Child Abuse \& Neglect 1986; 10 (1): 1986, 17-23 
4. Harned MS at all. Sexual assault and other types of sexual harassment by workplace personnel: A comparison of antecedents and consequences. Journal of Occupational Health Psychology 2002; 7(2), 174-188.

5. Vadisingha AN at el. A study on modes of communication in cases of sexual assault. Sri Lanka Journal of Forensic Medicine, Science \& Law. 2014;5(1)12-16

6. Bamford F, Roberts R. ABC of child abuse; Child Sexual Abuse 1l. British Medical Journal.
7. 1989;299(5):377-82

8. Emans SJ, Woods ER, Flagg NT, Freeman A. Genital findings in sexually

9. abused, symptomatic and asymptomatic, girls. Pediatrics. 1987;79 (5): 778-785

10. Joyce A, Harper K, Knudson S, Revilla J. Examination Findings in Legally Confirmed Child Sexual Abuse: It's Normal to be Normal. Pediatrics 1994; 94:310-317

11. Templeton DJ, Williams A. Current issues in the use of colposcopy for examination of sexual assault victims. Sex Health. 2006 ;3(1):5-10. 